ISSN 1027-5495. Functional Materials, 23, No.3 (2016), p. 509-516

doi:http://dx.doi.org/10.15407/fm23.03.509

(C) 2016 - STC “Institute for Single Crystals"

\title{
The influence of rotating magnetic field on the welding arc motion status
}

\author{
Zhi-gang Li ${ }^{1}$, Liang-ping Qiu ${ }^{1}$, Ji-zhong Liu ${ }^{2}$, \\ Jian-xiong $Y e^{3}$, Di-qing Wan ${ }^{1}$
${ }^{1}$ School of Mechanical Engineering, East China Jiaotong University, Jiangxi, Nanchang, 330013, P.R. China
${ }^{2}$ Jiangxi Robot \& Welding Automation key Laboratory, Nanchang
University, Jiangxi, Nanchang, 330013, P.R. China
${ }^{3}$ Electrical and Mechanical school, Nanchang Institute of Technology, Jiangxi, Nanchang, 330013, P.R. China

Received April 22,2016

\begin{abstract}
A device generating rotating magnetic field is designed on the bas is of the mechanism of a rotating magnetic field. A rotating magnetic field and electric arc jointing together simulation is studied in this paper to elaborate arc characteristics and behavior under the action of a rotating magnetic field. The rotation radius of the arc are inversely proportional to the rotational frequency of the magnetic field. It is proportional to the field current. Due to constraint function of its own magnetic field of underwater wet welding arc. The influence on the underwater welding arc is smaller than the air welding arc while the magnetic field rotation frequency and magnetic field intensity is changed.

Keywords: welding arc; rotational magnetic field; simulation; underwater wet welding

Разработано устройство для вращающегося магнитного поля на основе БАС механизма. Вращающееся магнитное поле и электрическая дуга сварки совместно исследуются в данной работе для получения характеристик дуги под действием вращающегося магнитного поля. Радиус поворота дуги обратно пропорџионален частоте вращения магнитного поля, но пропорџионален току возбуждения. Влияние водяного охлаждения на сварочную дугу меньше, чем воздушного, в то время как частота вращения магнитного поля и напряженность магнитного поля меняются.
\end{abstract}

Вплив магнітного поля, що обертаеться, на переміщення зварювальної дуги. Чжі-ганг Лi, Лян-пін Ці, Ці-чжун Лi, Пин-Сiн Liu, Дi-иин Ван

Розроблений пристрій для магнітного поля, що обертається, на основі БАС механізму. Магнітне поле, що обертається, і електрична дуга зварки спільно досліджуються в даній роботі для отримання характеристик дуги під дією магнітного поля, що обертається. Радіус повороту дуги обернено пропорційний частоті обертання магнітного поля, але пропорційний струму збудження. Вплив водяного охолоджування на зварювальну дугу менший, ніж повітря, тоді як частота обертання магнітного поля і напруженість магнітного поля міняються.

\section{Introduction}

It is well known that electric arc consists of free electrons and ion with positive and negative charge in the arc column area. It is characterized by electric neutrality, electrical con- ductivity and cooperating with magnetic field [1]. Therefore the position, shape and motion status of the arc can be controlled to better the welding process through additional magnetic field. In addition, there is a lot of high ionization gas in the arc for gas shielded welding. Its 
shape and behavior will be influenced under additional rotating magnetic field, thus the welding process will be affected. The study of rotating magnetic field is aiming to control the welding arc by the dynamic changing magnetic field to realize the idea of "combat dynamic with dynamic". Meanwhile, the welding process with additional magnetic field has the characters of additional device being simple, low cost, less energy consumption, etc [2]. On the basis of the generation of a rotating magnetic field, the influence of additional rotating magnetic field on arc (air welding arc and underwater wet welding arc which is under the high energy and high current density) movement characteristics and behavior is verified by simulation. As well as a judgment about the implementation process and control characteristics of a rotating magnetic field acting on the arc are made.

\section{Experimental}

\subsection{The generating of a rotating magnetic field}

Usually, a few excitation coil winding that mounts on the pairs of the magnetic pole as seen in Fig.1. When the pairs of excitation coil are applied by a certain of excitation current with phase difference, a rotating magnetic field is generated [2]. The form of the magnetic field is decided by the installation position of magnet exciting coil. The rotating frequency of the magnetic field is decided by the rotating frequency of magnet exciting coil and the value of the field is adjusted by exciting current. Here two pairs of magnetic poles are used to analyze the producing process of a rotating magnetic field. The sine excitation voltage is applied to the coil. The excitation voltage of a cycle is divided into four parts, corresponding to four kinds of stationary state of the rotating magnetic field. As shown in Fig. 2a, 2b, 2c, 2d, it is corresponds to the magnetic field distribution during $a, b$, c, d time period as in Fig 2. The excitation coil is given continuous excitation current and a rotating magnetic field surrounded by the space of the magnetic poles can be produced.

\subsection{Force Analysis of the Electric Arc}

When the arc is applied by rotating magnetic field, the force of the arc is shown in Fig. 4 [3]. DA three-dimensional coordinate system is established while the axis of the electrode being the $\mathrm{Z}$ axis, the direction of the magnetic field being the $\mathrm{X}$ axis, arc end at the anode being the origin of coordinates "O". Where Fh and Fm denote respectively restoring force and magnetic force of the arc itself, Fhy and Fhz denote the component of $\mathrm{Fh}$ in $\mathrm{Z}$ direction and $\mathrm{Y}$ direction respectively. Fmx, Fmy and Fmz are the elec-
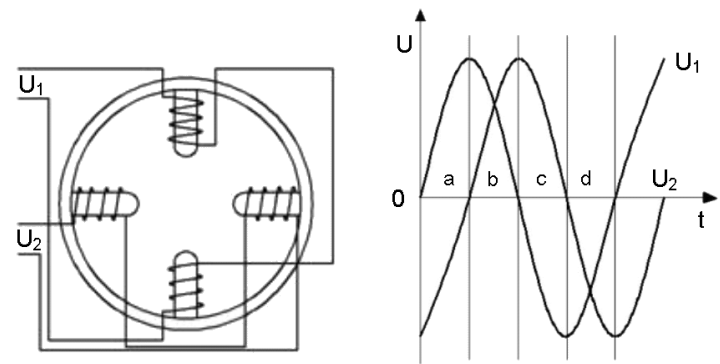

Fig. 1. Rotating magnetic field.

Fig. 2. Driving voltage
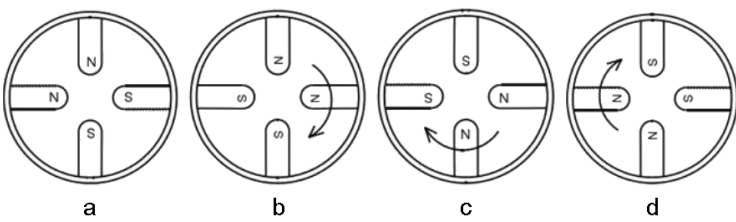

Fig. 3. Schematic diagram of the rotating magnetic field production process

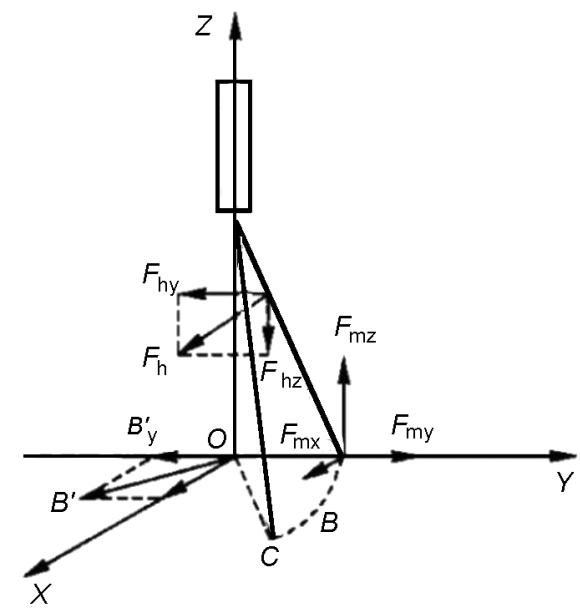

Fig. 4. Force analysis of the electric arc

tromagnetic force of the component force of $\mathrm{X}$, $\mathrm{Y}$, and $\mathrm{Z}$ direction formed by the magnetic field $\mathrm{B}$ and welding current I. The component force of Fm is Fmy and Fmz, which is arc stabilizing force. It can overcome the the restoring force $\mathrm{Fh}$ of arc itself, so that the arc deviates a certain distance from the axis of the electrode. Since the magnetic force Fmx is perpendicular to the welding current, it makes arc spin around the electrode axis. Therefore, arc is influenced by restoring force, steady arc force and rotating arc force together.

\subsection{The Design of a Rotating Magnetic Field Generator}

In order to solve the problem of the underwater wet welding arc unsteadiness, a rotating magnetic field generator is designed as shown in Fig. 5. The device can provide semi- dry environment and magnetic force constraints in the water environment, and stabilize the weld- 
ing arc in the water[4]. The arc stabilizing device is a cylindrical structure with a protective cover, it is all sealed except the gas and water inlet/outlet tube. The material of the protective cover is insulating with the conductive mouth. The center is a conductive rod with welding wire goes through and the shielding gas pipe around. The outer space has four iron cores with excitation coil on. The outer is high-pressure gas tube. Water is filled between around the core and cover, high-pressure tracheal wall. Water inlet pipe is for cooling water injecting, and water outlet pipe is for the environment water going through.

The whole device is placed in the water while working. The high pressure gas and the protective gas go through the high pressure inlet tube and the shielding air inlet tube respectively. The outer water goes through the water inlet tube. The welding voltage is introduced by the conductive mouth. Following the principle of stepping motors, when two sets of excitation current with different electric angle are used in the excitation coil, a rotating magnetic field can be produced in the space surrounding the two pairs of magnetic poles. Then the arc in the space will have a rotation, and the arc and molten drop constrained by the external magnetic field conditions is more stable. The high pressure gas displaces the water on the surface of welding workpiece and forms a local dry environment, thus protecting the internal arc less water intrusion from outside. The cooling water can prevent iron core from overheating, thus increasing the excitation effect.

\section{Results and discussion}

As shown in Fig. 6, the simulation model is built by ELEKTRA transient module in finite element analysis software OPERA. The simplified model only considers the influence of the magnetic field size and magnetic field distribution. There have been a lot of practice and achievements on the separate study of various factors on the magnetic field size and magnetic field distribution. Such as the influence by the installation of the excitation coil, the center of the core, the size of the excitation current, the diameter of the core and the angle of the magnetic pole etc [4]. The influence of rotating magnetic field upon arc is the magnetic field distribution and magnetic field intensity influence upon it in the final. Different magnetic field distribution and magnetic field intensity are produced by different rotating frequency and excitation current on the finite element simulation model shown in Fig. 6. The air welding arc and the underwater wet welding arc model are combined to study the arc characteristics and
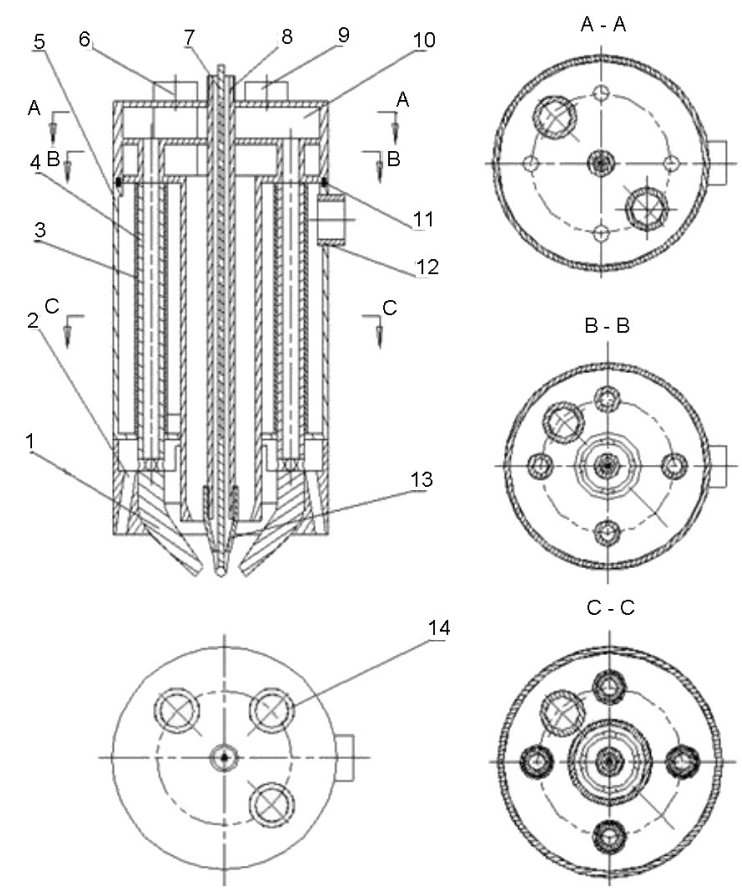

Fig. 5. Structure of arc stailizing device in the underwater wet welding. 1 - magnetizer, $2-$ high pressure gas outlets, 3 - magnet exciting coil. 4 - iron core, 5 - protective cover. 6 - water inlet tube, 7 - welding wire, 8 - conducting rod, 9 - high pressure air inlet tube, 10 - gas annular path, 11 - sealing ring, 12 - water outlet tube, 13 - conductive mouth, 14 - shielding gas inlet tube.

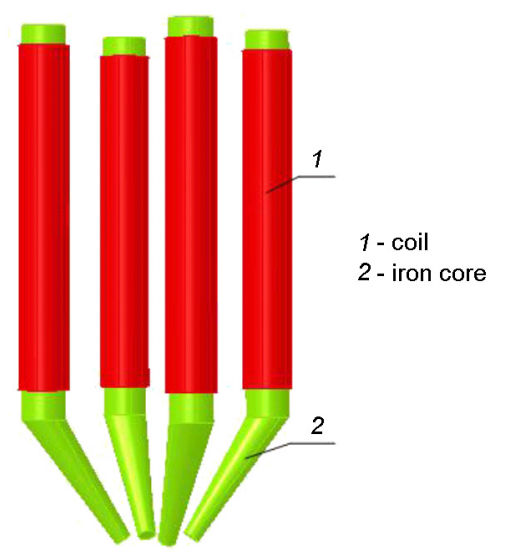

Fig. 6. OPERA ELEKTRA Transient simulation model

behavior under the action of a rotating magnetic field.

\subsection{Parameters Definition}

The needed parameters for the model calculation are the diameter of the coil and the total number of turns, the iron core B-H curve, the current and frequency of excitation. The Coil in the simulation model is represented by the square coil tightly arranged. In which the 


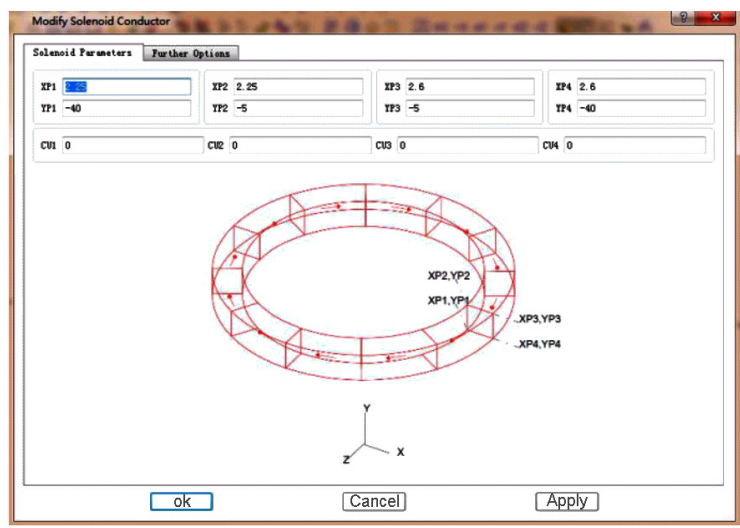

Fig. 7. Coil setting

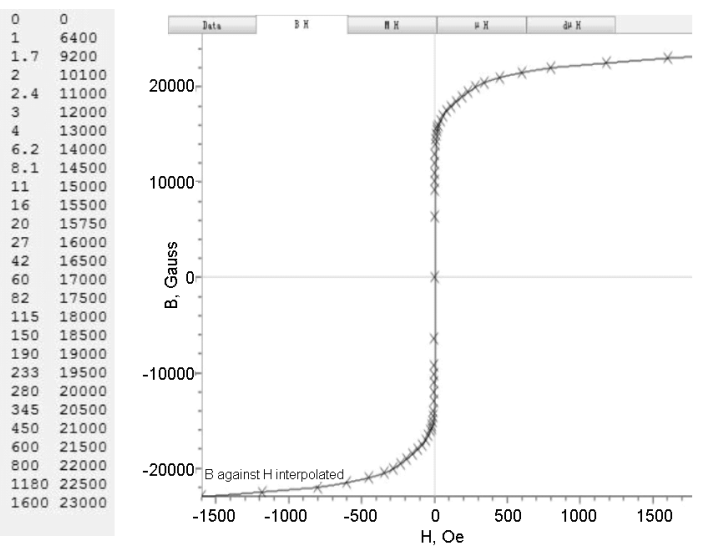

Fig.(8). B-H relation curve

square length is $0.5 \mathrm{~mm}$, the total number of turns of the coil is 140 .

The B-H curve is the magnetization curve, with magnetic field intensity $(\mathrm{H})$ as the abscissa, magnetic flux density (B) as the ordinate. Fig. 8 is B-H relation curve diagram of iron core. When the variable resistor (VR) moves down gradually, the coil current will increase. According to the formula of the $\mathrm{H}, \mathrm{H}$ within the core will gradually increase, B within the core also increases gradually.

Different magnetic field distributions and magnetic field intensity are obtained by mainly changing the current rotating frequency and the exciting current in the coil while the coil diameter, number of turns and $\mathrm{B}$ - $\mathrm{H}$ curve being constant in this paper. The parameter values at different rotating frequency and current are shown in Table 1 and Table 2 , respectively.

\subsection{The Simulation Result of the Rotat- ing Magnetic Field}

The result of the magnetic field vector of rotating magnetic field in different period in a load current cycle is shown in Fig. 9. With arrow down as $\mathrm{N}$ pole (shown as the shadow part in Fig.), arrow up as $\mathrm{S}$ pole. The N, S pole for columns 1,2,3,4 in Fig. 8 (a), (b), (c), (d) is re-
Table 1 The welding parameter values under different rotation frequency

\begin{tabular}{|c|c|c|c|c|}
\hline $\begin{array}{c}\text { param- } \\
\text { eters }\end{array}$ & $\begin{array}{c}\text { exciting } \\
\text { current, } \\
\mathrm{A}\end{array}$ & $\begin{array}{c}\text { rotation } \\
\text { frequency, } \\
\mathrm{Hz}\end{array}$ & $\begin{array}{c}\text { turns, } \\
\mathrm{n}\end{array}$ & $\begin{array}{c}\text { coil } \\
\text { diameter, } \\
\mathrm{mm}\end{array}$ \\
\hline 1 & 5 & 50 & 140 & 0.5 \\
\hline 2 & 5 & 400 & 140 & 0.5 \\
\hline
\end{tabular}

Table 2 The welding parameter under different driving current

\begin{tabular}{|c|c|c|c|c|}
\hline $\begin{array}{c}\text { param- } \\
\text { eters }\end{array}$ & $\begin{array}{c}\text { exciting } \\
\text { current, } \\
\mathrm{A}\end{array}$ & $\begin{array}{c}\text { rotation } \\
\text { frequency, } \\
\mathrm{Hz}\end{array}$ & $\begin{array}{c}\text { turns, } \\
\mathrm{n}\end{array}$ & $\begin{array}{c}\text { coil } \\
\text { diameter, } \\
\mathrm{mm}\end{array}$ \\
\hline 1 & 3 & 50 & 140 & 0.5 \\
\hline 2 & 5 & 50 & 140 & 0.5 \\
\hline
\end{tabular}
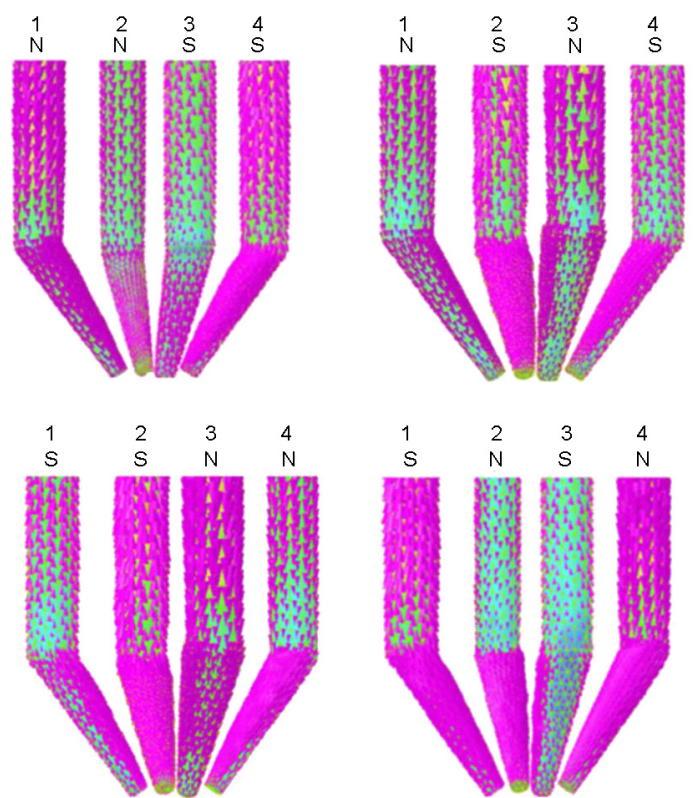

Fig. 9. Vector result of a rotational magnetic field

spectively NNSS,NSNS,SSNN,SNSN. It is the same with the generation of a rotating magnetic field shown in Fig. 3.

The movement behavior of the welding arc under a rotating magnetic field is mainly studied here. The arc used here has been simulated and the specific detail will not be described here. The air welding arc and underwater wet welding arc are shown in Fig. 10 and Fig. 11. As it can be seen that the welding arc in the air appears to be "bell", while the arc underwater appears to be "dumbbell"[5]. It is the own strong magnetic fields due to the high power used in the underwater wet welding that makes the arc shrink obviously. The underwater wet welding is a welding with a high energy and high current density. The arc magnetic fields produced by itself have very important influence on arc, 


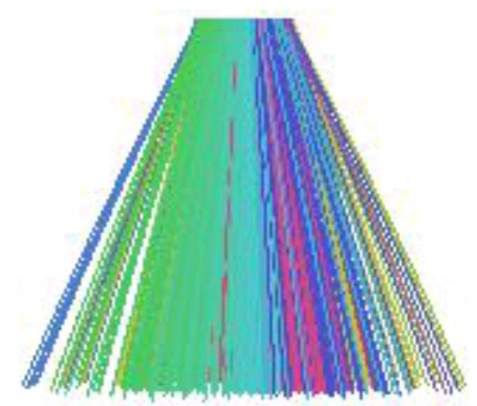

Fig. 10. Air welding arc shape

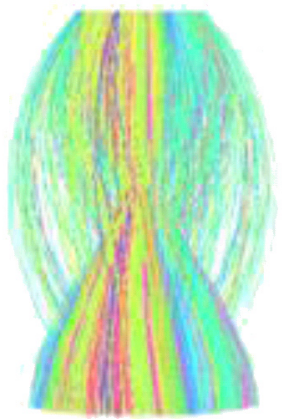

Fig. 11. Underwater welding arc shape

so it usually can't be ignored. The relation between the magnetic effect produced by arc and charged iron beam is modeled with Biot-Savart's law demonstrated in Equation1[6]:

$$
\begin{aligned}
\vec{B}(\vec{r}) & =\frac{\mu_{0}}{4 \pi} \int \frac{\vec{j}(\vec{r}) *\left(\vec{r}-\vec{r}^{\prime}\right)}{|\vec{r}-\vec{r},|^{3}} d^{3} r^{\prime}= \\
& =\frac{\mu_{0}}{4} \int \frac{I d l * \vec{r}}{r^{3}}
\end{aligned}
$$

Where:

I is the current; $\mathrm{dl}$ is a differential element of the current direction; $\mu_{0}$ is the magnetic constant; $\vec{r}$ is the unit displacement vector; $r$ is the distance from the element to the point where the field is being computed.

\subsection{The combination simulation of a} rotating magnetic field and electric arc

The simulation of the air welding arc and the underwater wet welding arc in the rotating magnetic field is done. A certain practical and theoretical foundation for the study of the rotating magnetic field and arc characteristics and its behavior is established through comparing the simulation result with other researchers' experiment result.

In order to study the influence upon the arc motion status by the rotating magnetic field under the condition of different magnetic field distribution and magnetic field intensity, the value of the excitation frequency and current is adjusted by the rotation of the rotating magnetic field frequency and the value of the mag-
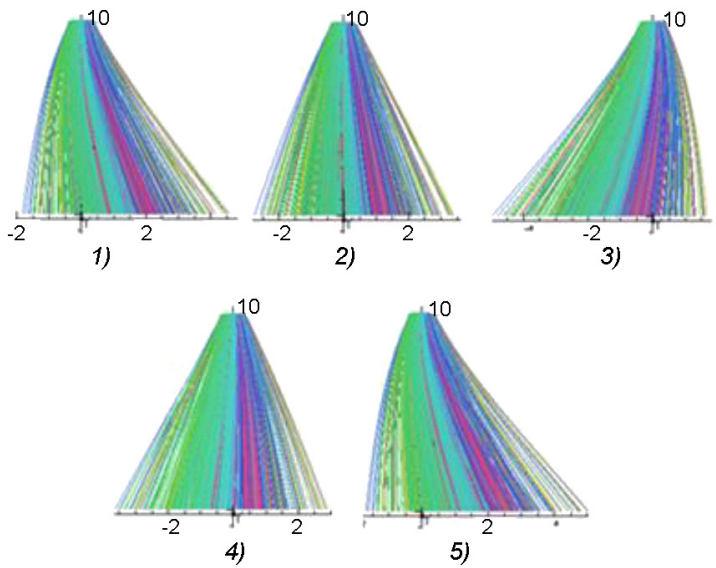

Fig. 12. Arc motion morphology in a rotational cycle under the rotation frequency of $50 \mathrm{~Hz}$

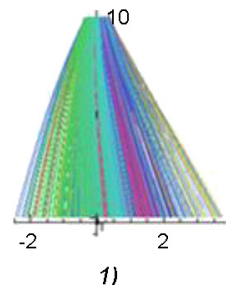

1)

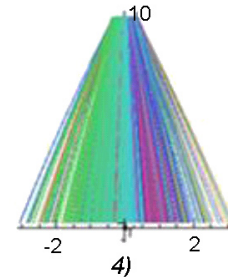

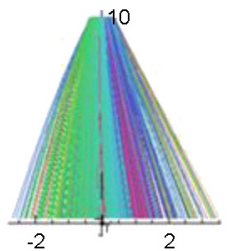

2)

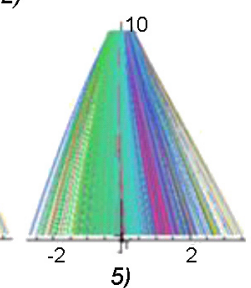

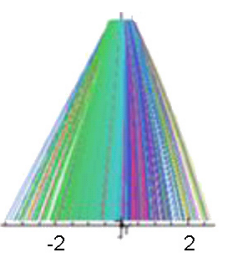

3)
Fig. 13. Arc motion morphology in a rotational cycle under the rotation frequency of $400 \mathrm{~Hz}$

netic field strength. The Co-Simulation needs importing the data of the rotating magnetic field and combining with the data of arc under the SCALA module of OPERA[7].

\subsection{The rotation frequency of the mag-} netic field influence on welding arc behavior

The excitation current in the simulation conditions is designated as $5 \mathrm{~A}$. The tungsten wire diameter is $1.6 \mathrm{~mm}$, the arc length $3 \mathrm{~mm}$. Dc is used. The air welding arc motion status in a rotating cycle while the rotation of the magnetic field frequency being $50 \mathrm{~Hz}$ is shown in Fig. 12. While the frequency being $400 \mathrm{~Hz}$, it is shown in Fig. 13. In the literature [8], the air welding arc motion status in a rotating cycle is shown in Fig. 14 in the case of the same other conditions, where the rotation of the magnetic field frequency is $50 \mathrm{~Hz}$, the high-speed camera adopts 500 FPS. The arc in the experiment is collected as a high-speed video clips within a rotating magnetic field. In the literature [4], the air welding arc motion status in a rotating cycle is shown in Fig. 15 in the case of the same other 


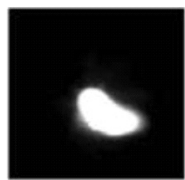

1)

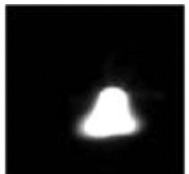

5)

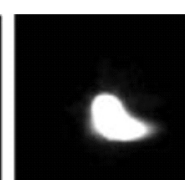

2)

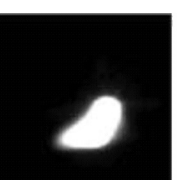

6)

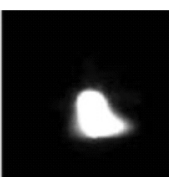

3)

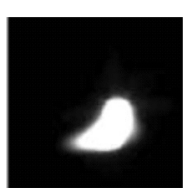

7)

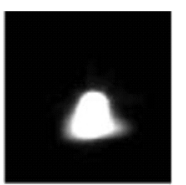

4)
Fig. 14. Arc motion morphology in a rotational

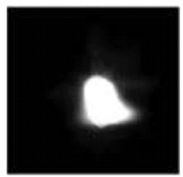

1)

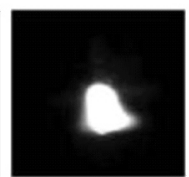

2)

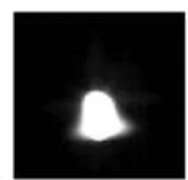

3)

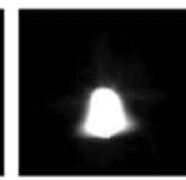

4)

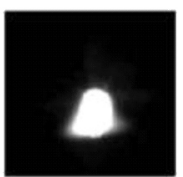

5)

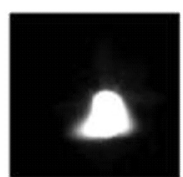

6)

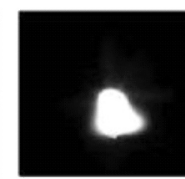

7)
Fig. 15. Arc motion morphology in a rotational cycle under the rotation frequency of $400 \mathrm{~Hz}$

conditions, where the rotation of the magnetic field frequency is $400 \mathrm{~Hz}$, the high-speed camera adopts 2000 FPS. The arc in the experiment is also collected as a high-speed video clips within a rotating magnetic field. The underwater wet welding arc motion status in a rotating cycle while the rotation of the magnetic field frequency being $50 \mathrm{~Hz}$ is shown in Fig. 16. While the frequency being $400 \mathrm{~Hz}$, it is shown in Fig. 17.

The above simulation results shows that the arc rotation frequency is identical with the magnetic field rotation frequency, and the rotation of the arc radius is inversely proportional to the rotation of the magnetic field frequency. The greater the rotation frequency of the magnetic field, the smaller the radius of the arc. With the increase of rotating frequency, it is more obvious. The change of the rotating magnetic field frequency impacts more on air welding arc than the underwater wet welding arc. The simulation results of the magnetic field rotation frequency impacting on the arc motion status are consistent with the experiment conclusion in the literature[8]. It proves the correctness of the simulation from another aspect.

\subsection{The influence of the magnetic field strength upon the welding arc motion status}

The rotation of the magnetic field frequency in the simulation conditions is designated as

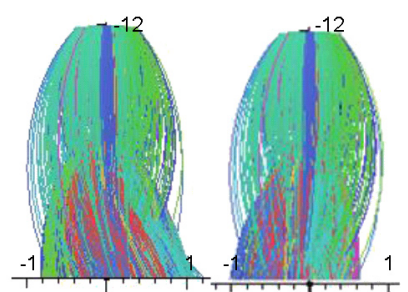

(1)

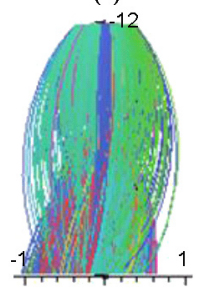

(4)

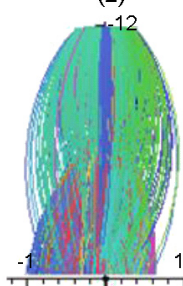

(5)

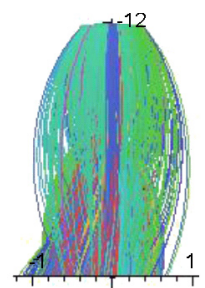

(3)

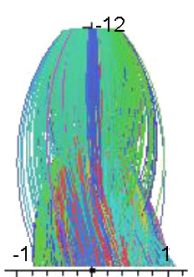

(6)
Fig. 16. Arc motion morphology in a rotational cycle under the rotation frequency of $50 \mathrm{~Hz}$

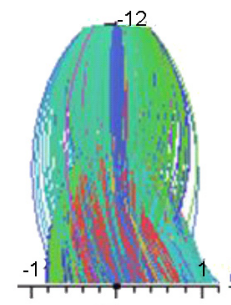

(1)

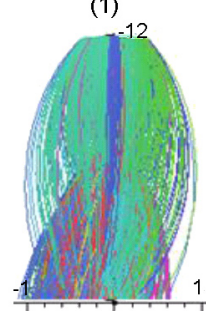

(4)

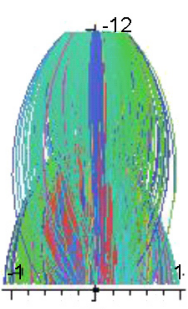

(2)

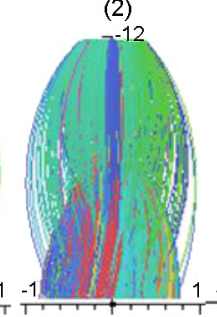

(5)

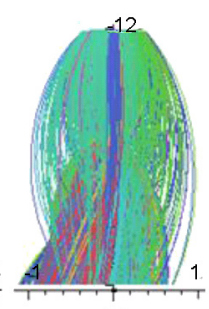

(3)
Fig. 17. Arc motion morphology in a rotational cycle under rotation frequency of $400 \mathrm{~Hz}$

$50 \mathrm{hz}$. The tungsten wire diameter is $1.6 \mathrm{~mm}$, the arc length $3 \mathrm{~mm}$. Dc is used. The air welding arc motion status in a rotating cycle while the rotation of excitation current being $3 \mathrm{~A}$ are shown in Fig. 18. In the literature [8], the air welding arc motion status in a rotating cycle is shown in Fig. 19 in the case of the same other conditions, where the rotation of excitation current being is $3 \mathrm{~A}$, the high-speed camera adopts 500 FPS. The arc in the experiment is collected as a high-speed video clips within a rotating magnetic field. In [5], the air welding arc motion status in a rotating cycle are shown in Fig. 20 in the case of the same other conditions, where the rotation of excitation current being is $5 \mathrm{~A}$, the high-speed camera adopts 2000 FPS. The arc in the experiment is also collected as a high-speed video clips within a rotating magnetic field. The underwater wet welding arc motion status in a rotating cycle while the rota- 


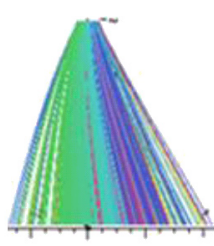

1)

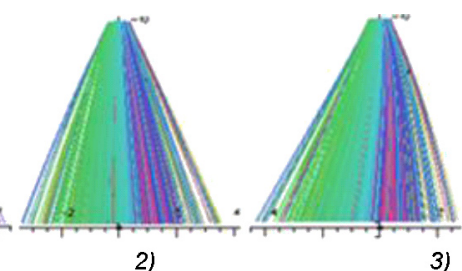

2)

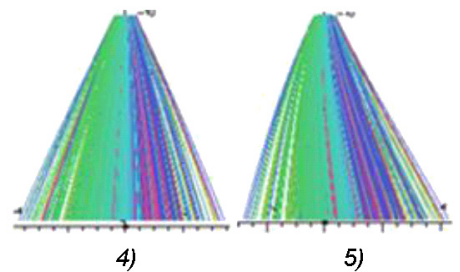

Fig. 18. Arc motion morphology in a rotation cycle under the exciting current $3 \mathrm{~A}$

tion of the rotation of excitation current being $3 \mathrm{~A}$ is shown in Fig. 21.

The above simulation results shows that the arc rotation radius are identical with the rotation magnetic field strength while the rotation frequency is the same. The greater the rotation magnetic field strength, the larger the rotation radius of the arc. The change of the rotating magnetic field strength impacts more on air welding arc than the underwater wet welding arc. The simulation results of the rotation magnetic field strength impacting on the arc motion status is consistent with the experimental conclusion in the literature[8] . It proves the correctness of the simulation from another aspect.

\section{Conclusions}

The combination simulation of a rotating magnetic field and electric arc shows that:

a. The rotation of the arc frequency changes with the rotation frequency of the magnetic field. The rotation of the arc radius is inversely proportional to the rotation of the magnetic field frequency. The greater of the rotation frequency of the magnetic field, the smaller the rotation radius of the arc.

b. The value change of the field current can change arc motion status. The rotation radius of the arc increase with the grow of excitation current. So different rotating arc motion status can be obtained by adjusting the value of the excitation current.

c. Due to the constraint function of its own magnetic field of underwater wet welding arc, the influence of the rotation frequency of the magnetic field or magnetic field intensity upon the underwater welding arc movement is smaller than the air arc.

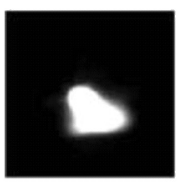

1)

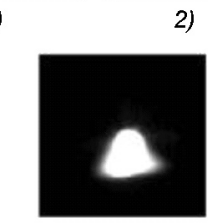

5)

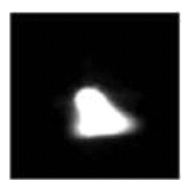

2)

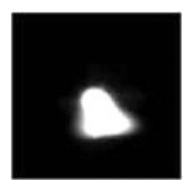

3)

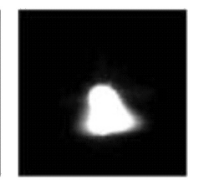

4)

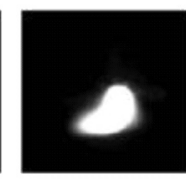

6)

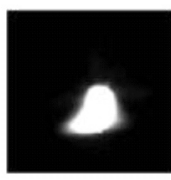

7)
Fig. 19. Arc motion morphology in a rotation cycle under the exciting current $3 \mathrm{~A}$

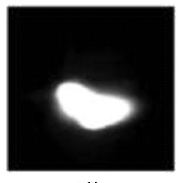

1)

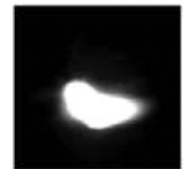

2)

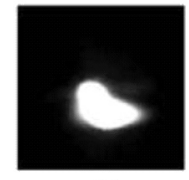

3)

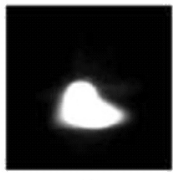

4)

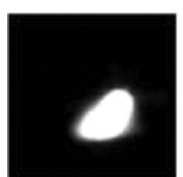

5)

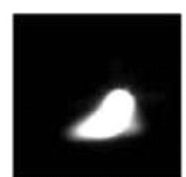

6)

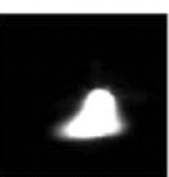

7)
Fig. 20. Arc motion morphology in a rotation cycle under the exciting current $5 \mathrm{~A}$

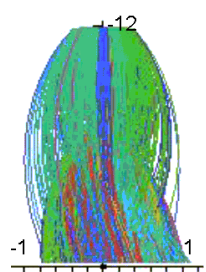

(1)

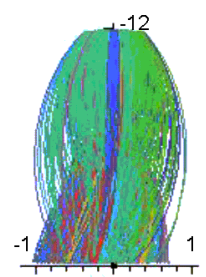

(4)

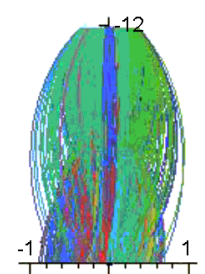

(2)

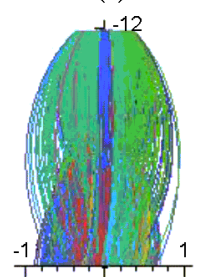

(5)

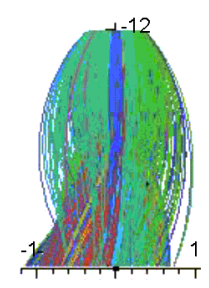

(3)

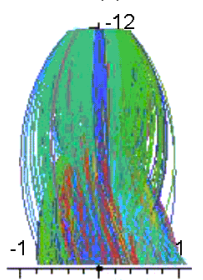

(6)
Fig. 21. Arc motion morphology in a rotation cycle under the exciting current $3 \mathrm{~A}$

\section{Acknowledgements}

This work is supported by the Nation 7 al Natural Science Foundation of China(No.51665016) and funded by the China Scholarship. And also by Natural Science Founda 7 tion of Jiangxi Province (20132BAB206028) and Natural Science Foundation of Jiangxi Province (20151BAB207047). 


\section{References}

1. Descoeudres, Antonine. Characterization of Electrical Discharge Machining Plasmas, P.H.D. thesis, Ecole Polytechnique Federale De LaUSaNNE, Lausanne, ON, France, 2006.

2. GuiYun-Qi. Study on characteristic and movement behavior of welding arc under rotating magnetic field, M.S. thesis, Beijing University of Technology, Beijing, ON, China, 2004.

3. A.D. Razmyshlyayev, M.V. Mironova, S.V. Yarmonov, P.A.Vydmysh, Welding Int., 29(4), 296, 2015.

4. Zhigang-Li, Huifang-Jia, Jizhong-Liu. Welding Techn., 42(9), 47, 2013.

5. Christopher J. Lewis. Development of a numerical simulation tool for modeling a DC arc discharge in a liquid dielectric media, P.H.D. thesis, Brigham Young University, Utah, ON, America, 2010.
6. Boxman, Raymond L, Philip J Martin, David M Sanders. Handbook of Vacuum Arc Science and Technology, Fundamentals and Applications, Park Ridge, New Jersey, Noyes Publications, 1995.

7. Vector Fields, Opera-3d Reference Manual. Software Reference Manual,Vector Fields, 20082009.

8. Xuezheng-Wang. Design of a device for generating rotating magnetic field used to control welding arc, M.S. thesis, Beijing University of Technology, Beijing, ON, China, 2004.

9. Shi Chuanwei, Zou Yong, Zou Zengda, et al, J. Mater. Proc. Techn., 214, 2292, 2014.

10. Lang, Wen Chang, Bai Zhong Wu, Bin Gao. Appl. Mech. Mater., 152(154), 1698, 2012.

11. Sun, Qing Jie, Hai Feng Hu, Xin Yuan, Ji Cai Feng. Adv. Mater. Res., 308(310), 1170, 2011.

12. Wang, Xu Ming, Wei Liang, Su Hong Sun. Adv. Mater. Res.,675, 148, 2013. 